\title{
Mechanisms Generating Diversity in Glucocorticoid Receptor Signaling
}

\author{
Javier R. Revollo and John A. Cidlowski \\ Molecular Endocrinology Group, Laboratory of Signal Transduction, National Institute \\ of Environmental Health Sciences (NIEHS)/NIH, Research Triangle Park, \\ North Carolina, USA
}

\begin{abstract}
Glucocorticoids regulate diverse biological processes throughout the body via the glucocorticoid receptor (GR). Ligand-bound GR translocates into the nucleus and can elicit changes in gene expression by direct contact with the DNA or by protein-protein interactions with other transcription factors. The GR can also mediate rapid nongenomic signaling events initiated in the cytoplasm. In this chapter, we review the biological and physiological implications of glucocorticoids, the GR, and many of the signal transduction mechanisms that mediate their action.
\end{abstract}

Key words: glucocorticoids; signaling; glucocorticoid receptor

\section{Introduction}

Essential to human life, glucocorticoids are steroid hormones that allow us to cope with a variety of environmental and physiological stresses. Glucocorticoids are produced and released by the adrenal cortex under the control of the hypothalamic-pituitary-adrenal axis (HPA). When the body perceives stress, the hypothalamus releases corticotropin-releasing hormone $(\mathrm{CRH})$ that stimulates the release of adrenocorticotropic hormone (ACTH) from the pituitary gland. The adrenal cortex, in turn, synthesizes glucocorticoids in response to ACTH. Thus, glucocorticoids are ultimately part of an adaptive response that seeks to maintain homeostasis during stressful situations. Indeed, the most notable physiological reactions to glucocorticoids, increased glucose production and immunosuppression, are responses to some of the most common insults the human body encounters, namely low blood glucose and inflammation, respectively. ${ }^{1,2}$

Address for correspondence: John A. Cidlowski, NIEHS, MD F3-07, P.O. Box 12233, Research Tringle Park, NC 27709. cidlows1@niehs.nih.gov
Once produced by the adrenal cortex, glucocorticoids are released into the bloodstream and bind corticosteroid-binding globulins to be distributed throughout the body. Due to their hydrophobic nature, glucocorticoids readily diffuse from the circulation into organs, tissues, and cells. Intracellularly, glucocorticoids interact with the ubiquitously expressed glucocorticoid receptor (GR) to orchestrate a vast array of responses at the cellular level that culminate in changes in metabolism (carbohydrate, protein, and lipid), immune system function, vascular tone, bone mineralization, and central nervous system function, among others. ${ }^{1}$

Dysregulation of glucocorticoid production, as seen in Cushing's or Addison's disease, can lead to severe complications and ultimately death. Cushing's disease is characterized by overproduction of glucocorticoids in the adrenal cortex as a result of high ACTH levels because of a pituitary gland tumor. The disease is characterized by weight gain, increased fat mass, hyperglycemia, reduced muscle and bone mass, immunosuppression, and water retention. Untreated, these symptoms can lead to diabetes, hypertension, heart failure, edema, and infection. Surgical removal of the pituitary 
tumor is the only successful treatment for Cushing's disease. $^{3}$

Addison's disease, in contrast, is characterized by decreased production of glucocorticoids, leading to hypocortisolism. It is generally caused by developmental defects or trauma to the adrenal cortex that results in the deficient production and secretion of glucocorticoids and mineralocorticoids. Symptoms include weight loss, hypoglycemia, and alteration of sodium and potassium levels. Addison's disease can be successfully treated with glucocorticoid- and mineralocorticoidreplacement therapy. ${ }^{4}$

Largely due to their powerful immunosuppressant activity, many synthetic glucocorticoids have been developed and are currently in therapeutic use. These compounds are some of the most commonly prescribed drugs in the world today. They are used in the treatment of many hematological cancers as well as in asthma, allergic rhinitis, ulcerative colitis, rheumatoid arthritis, eczema, and psychological disorders of the brain. Unfortunately, due to their broad range of physiological actions, long-term use of glucocorticoids is invariably accompanied by adverse side effects that bear close resemblance to Cushing's disease. Currently, a considerable amount of research seeks to generate synthetic glucocorticoids with more targeted actions and reduced side effects.

\section{The Glucocorticoid Receptor Gene}

The GR is a steroid hormone receptor that belongs to the nuclear receptor superfamily of transcription factors. It is related to other steroid receptors, such as the mineralocorticoid, androgen, estrogens, progesterone, vitamin D, and retinoic acid receptors. ${ }^{5}$ These steroid receptors are evolutionarily conserved in mammals and believed to have originated by multiple gene duplications from a common ancestor in a process that began 400 million years ago. ${ }^{6}$
The GR is essential for life, as illustrated by multiple GR knockout mouse models. ${ }^{7-9}$ Whole body deletion of exon 2 of the mouse GR gene results in severe developmental abnormalities in the lung that lead to death within hours of birth. ${ }^{7}$ More recently, the GR has also been disrupted in a tissue-specific manner by deletion of either exon 2 or exon 3. In the liver, GR has been shown to be responsible for gluconeogenic metabolism, as well as insulin-like growth factor (IGF)-1 production required for postnatal growth. ${ }^{10,11}$ Central nervous systemdeficient GR mice exhibit dysregulation of the HPA axis and develop a number of physiological and behavioral abnormalities that mimic depressive disorders. ${ }^{12,13}$ Furthermore, deletion of GR in $\mathrm{T}$ cells seems to be dispensable for $\mathrm{T}$ cell development but results in increased mortality upon immune activation due to dysregulation of several cytokines. ${ }^{8}$ Similarly, macrophage GR-deficient mice also exhibit severe mortality caused by increased cytokine production in response to activation of inflammatory signaling. ${ }^{9}$ Finally, osteoclast GR-null mice develop normally and are protected from glucocorticoid-suppressed bone formation. ${ }^{14}$

The human GR (hGR) gene is located on chromosome 5 (region $5 \mathrm{q} 31 \mathrm{p}$ ) and is composed of 9 exons (Fig. 1A). ${ }^{15,16}$ In the mature mRNA, exon 1 represents the $5^{\prime}$-untranslated region, while exons 2-9 code for the protein and the $3^{\prime}$-untranslated regions (Fig. 1B). Exon 1 is composed of several independent variants termed $1 \mathrm{~A}-1 \mathrm{~J}$, each of them containing its own transcriptional start sites and unique promoters. ${ }^{17,18}$ Interestingly, none of these promoters contain classical TATA- or CCAATboxes. ${ }^{15,17-19}$ The varieties of promoters, transcription factor-binding sites, and transcriptional start sites are thought to account for the differences in gene expression of hGR throughout the body. Similar to exon 1, exon 9 can be alternatively spliced to produce the two most widely known isoforms: hGR $\alpha$ and hGR $\beta$ (Fig. 1B). ${ }^{16}$

Isoforms hGR $\alpha$ and $\mathrm{hGR} \beta$ are identical up to amino acid residue 727 , but differ on their 


\section{A Structure of hGR gene}

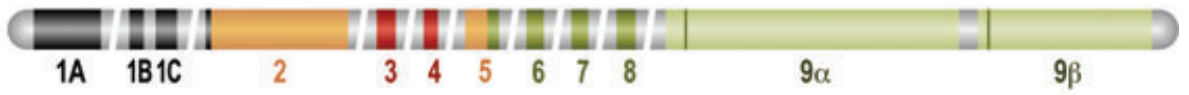

\section{B Alternative mRNA splicing}

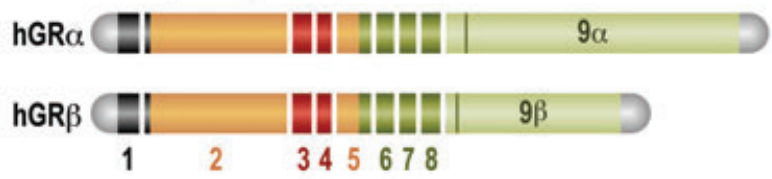

\section{Alternative initiation sitesof hGR $\alpha$ protein}

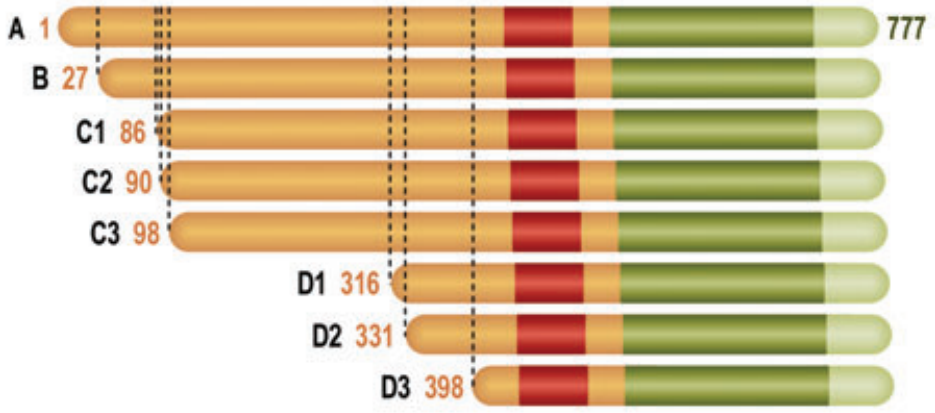

\section{Domain structure of $h \mathrm{GR} \alpha$ protein}

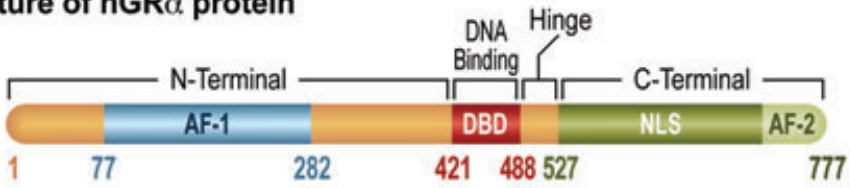

\section{E Post-translational modification of hGR $\alpha$ protein}

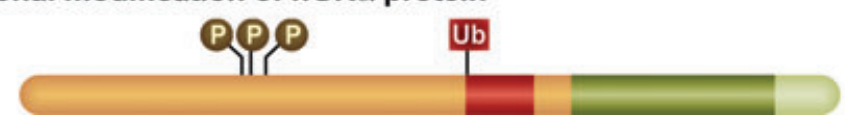

Figure 1. The hGR gene codes for multiple isoforms. (A) The hGR gene is located in chromosome 5 (region $5 q^{3} 1 \mathrm{p}$ ) and is composed of nine exons. Exons 1 and 9 contain multiple variants. (B) Alternative splicing of exon 9 gives rise to the mRNA messages of the two most characterized hGR isoforms-hGR $\alpha$ and hGR $\beta$. (C) Alternative initiation sites can give rise to seven more isoforms from each mRNA message. (D) The domain structure of full-length $h G R \alpha$, or $h G R \alpha-A$. It is composed of an N-terminal region, a DNAbinding domain, a hinge region, and a $\mathrm{C}$-terminal region. The $\mathrm{N}$-terminal region contains an $\mathrm{AF}-1$ domain able to interact with the basal transcriptional machinery. The DNA-binding domain contains two zinc fingers involved in dimerization and interacts with the DNA. The hinge region contains NLS. The C-terminal domain contains the ligand-binding motif, an NLS, and an AF-2 involved in interactions with various transcriptional regulatory factors. (E) Phosphorylation of serines 203, 211 , 226, and ubiquitination of lysine 426 are known post-translational modifications of $h G R \alpha$. 
carboxy termini. The predominant isoform is $\operatorname{hGR} \alpha$ and is composed of 777 amino acid residues. It is capable of binding endogenous glucocorticoids and mediating a variety of signaling mechanisms. In contrast, hGR $\beta$ is only 742 amino acids long and generally expressed at much lower levels than hGR $\alpha .{ }^{20}$ While the physiological relevance of $\mathrm{hGR} \beta$ is unclear, it is believed to act as a dominant negative regulator of hGR $\alpha .^{21}$ Higher expression of hGR $\beta$ has been associated with cardiovascular disease, as well as glucocorticoid-resistant asthma, ulcerative colitis, and rheumatoid arthritis. ${ }^{22}$ $\mathrm{hGR} \beta$ is unable to bind any known glucocorticoids and reported to be transcriptionally inactive. Recent studies have shown that hGR $\beta$ can bind RU-486, a synthetic glucocorticoid antagonist. Moreover, the mere expression of $\mathrm{hGR} \beta$ is sufficient to elicit changes in gene expression, and many of these changes largely disappear in the presence of RU-486. ${ }^{23}$ Other splice variants have been identified and code for isoforms hGR $\gamma$, hGR-A, and hGR-P. ${ }^{24-26}$ However, their expression level is low in comparison to $\mathrm{hGR} \alpha$, and their physiological role is unclear.

Additional GR isoforms are also generated by alternative translation initiation of the mature mRNA (Fig. 1C). These isoforms are created when the ribosome skips an upstream initiation codon, either by leaky scanning or ribosomal shunting, and starts translation from an alternative initiation site located further downstream in the mRNA message. The resulting protein isoforms exhibit progressively shorter N-terminal regions, but have identical amino acid sequences downstream of the alternative initiation sites. The hGR $\alpha$ and $\mathrm{hGR} \beta$ mRNA transcripts can each give rise to eight translational isoforms, many of which exhibit different tissue-expression patterns and mediate unique transcriptional responses. ${ }^{27,28}$

\section{Protein Structure}

$\mathrm{GR} \alpha$ is a modular protein and is comprised of three domains: the N-terminal transacti- vation domain, the central DNA-binding domain, and the C-terminal ligand-binding domain (Fig. 1D). The N-terminal domain contains the AF-1 (activation function) motif that can physically interact with the basal transcriptional machinery to mediate gene activation. ${ }^{29}$ The DNA-binding domain harbors two zinc finger motifs and is required for receptor dimerization as well as interactions with the DNA. ${ }^{30}$ The C-terminal domain contains the ligand-binding motif, a nuclear localization signal (NLS), and a second activation function motif (AF-2) involved in interactions with various transcriptional regulatory factors. ${ }^{30}$ Crystal structures have revealed that the ligand-binding motif is a hydrophobic pocket created by numerous $\alpha$-helices and $\beta$-sheets. ${ }^{31}$ In addition to these three large domains, there is a small flexible portion of the protein called the hinge region. It is located between DNA-binding and the C-terminal domains and contains an additional NLS. ${ }^{30}$

The GR $\alpha$ protein can also be modified posttranslationally by phosphorylation, sumoylation, and ubiquitination (Fig. 1E). ${ }^{32}$ Phosphorylation of $\mathrm{hGR} \alpha$ at serines 203, 211, and 226 leads to changes in its subcellular localization and ability to interact with other proteins, whereas ubiquitination of lysine 426 alters its cellular half-life. ${ }^{33-35}$ The exact physiological relevance of these and other posttranslational modifications of $\mathrm{GR} \alpha$ remain to be established; however, it is widely believed that they can modify glucocorticoid signaling.

Based on the presence or absence of hormone ligand, intracellular GR $\alpha$ appears to exist in two conformations (Fig. 2). In the first, the receptor is ligand unbound and sequestered in the cytoplasm in a multimeric complex composed of hsp90, hsp56, hsp40, p23, Src, and others. ${ }^{36,37}$ This complex keeps the receptor in a conformation poised to bind its ligand and conceals the NLSs. Ligand binding (glucocorticoids) induces a conformational change in $\mathrm{GR} \alpha$ that leads to its dissociation from the multimeric complex and exposes its NLSs, 


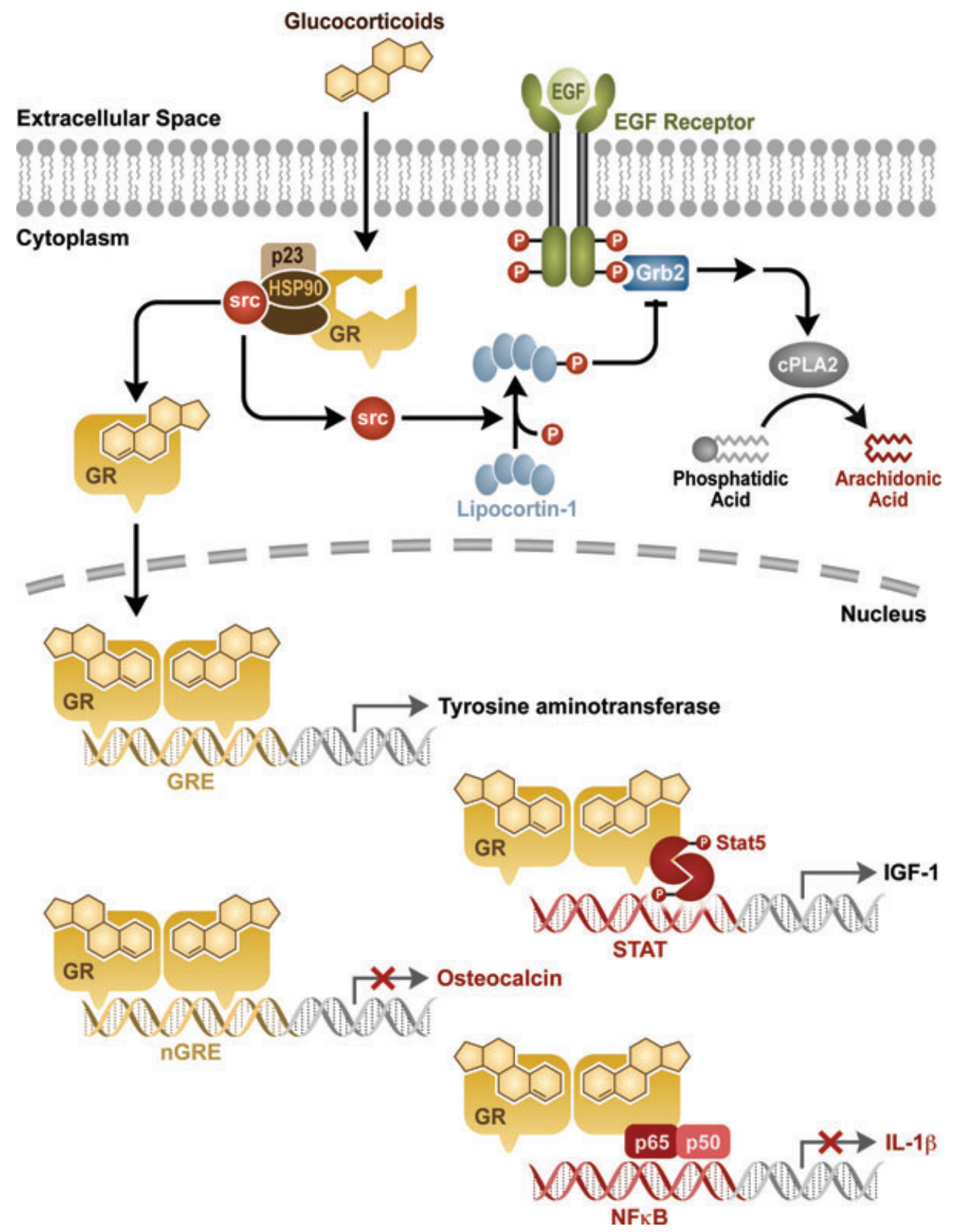

Figure 2. Glucocorticoid signaling results in changes in gene expression and rapid nongenomic events in the cytoplasm. Ligand binding to the GR leads to the dissociation of a cytoplasmic complex interacting with GR. Ligand-bound GR rapidly translocates into the nucleus, where it can activate gene expression by directly binding to GREs in the DNA, or associate with transcription factors, such as STAT5. GR can also promote gene silencing by directly interacting with nGREs in the DNA, or by protein-protein interactions with transcription factors, such as NFKB. In the cytosol, the dissociation of the protein complex interacting with $G R$ leads to the release of src kinase, which phosphorylates lipocortin-1. Phosphorylated lipocortin-1 displaces Grb2 from the activated EGF receptor to inhibit the activation of $\mathrm{CPLA}_{2}$ and the creation of arachidonic acid. 
resulting in its rapid translocation into the nucleus. $^{36}$

\section{Gene Activation by Direct DNA Binding}

In the nucleus, ligand-bound GR $\alpha$ dimerizes and binds to the DNA in a sequencespecific manner. The DNA sequences where GR $\alpha$ binds are called glucocorticoid response elements, or GREs, and are characterized by similarity to the 15-bp consensus sequence $5^{\prime}$ AGAACAnnnTGTTCT-3' (Fig. 2). However, in numerous genes, GRE half-sites are sufficient to elicit GR $\alpha$-mediated transcriptional changes. ${ }^{38}$ Multiple GREs are usually distributed in the proximal promoters of target genes, but their numbers and location can vary substantially. ${ }^{39,40}$ DNA binding by GR $\alpha$ induces a conformational change in the receptor that results in the physical association with a variety of coregulatory factors and their recruitment to the chromatin. $^{2}$

Several mechanisms exist by which GR $\alpha$ and DNA interactions promote gene induction. First, if the GRE is in close proximity to the TATA-box, hGR $\alpha$ can recruit key components of the basal transcriptional machinery to the TATA-box, such as Transcription Factor IID, and thus directly promote gene activation. $^{41}$ If the GRE is located at a distance of the TATA element, hGR $\alpha$ can associate with coactivators that function as bridges to promote the recruitment of the basal transcriptional machinery. ${ }^{42,43}$ Furthermore, GR $\alpha$ can also recruit chromatin-remodeling coactivators that alter the nucleosomal structure of the DNA and create a more favorable environment for gene expression. Some of these coactivators, such as CBP, p300, p/CAF, and SRC1 , are histone acetyl transferases (HATs), while others, such as SWI/SNF, are ATP-dependent chromatin remodeling factors. ${ }^{44,45}$ Examples of genes positively regulated by GREs include tyrosine aminotransferase, alanine aminotrans- ferase, and phosphoenolpyruvate carboxykinase, all involved in liver gluconeogenesis.

\section{Gene Activation by Protein-Protein Interactions}

$\mathrm{GR} \alpha$ can also regulate gene activity independent of DNA binding via protein-protein interactions with other transcription factors (Fig. 2). GR $\alpha$-dependent gene activation by this mechanism is best illustrated by Signal Transduction and Transcription proteins (STATs). STATs are transcription factors involved in the Janus kinase (JAK) signaling pathway. Activation of JAK signaling results in the phosphorylation and dimerization of STATs, leading to their translocation into the nucleus and subsequent interaction with their response elements in the DNA. ${ }^{46}$ It has been shown that STAT- 5 physically interacts with $\mathrm{GR} \alpha$. In this case, STAT-5 is directly associated with the DNA, while GR $\alpha$ is recruited to the chromatin without it directly interacting with the DNA. The GR $\alpha-$ STAT- 5 association leads to activation of several genes, most notably IGF-1 in the liver that is required for postnatal growth. ${ }^{11} \mathrm{GR} \alpha$ is also capable of interacting with STAT-3 and -6 to promote gene activation. ${ }^{47,48}$

\section{Gene Repression by Direct DNA Binding}

Direct DNA binding by GR $\alpha$ can also lead to repression of genes by interactions with negative GREs (nGREs) (Fig. 2). nGREs are similar to GREs and almost always are located in close proximity to DNA-binding sites for other transcription factors necessary for gene expression. As a result, hGR $\alpha-n G R E$ interactions lead to gene silencing by competing with, and displacing, other transcription factors from the DNA. The osteocalcin gene promoter, for instance, contains an nGRE that overlaps with its TATA box, and GR $\alpha$ association with this site 
prevents access from the basal transcriptional machinery. ${ }^{49}$ Similarly, the human FasL gene contains an nGRE adjacent to a nuclear factorк B $(\mathrm{NF} \kappa \mathrm{B})$ site. $^{50} \mathrm{GR} \alpha-\mathrm{nGRE}$ association in this site prevents NFKB binding and induces gene silencing. Despite the fact that nearly half of the genes regulated by glucocorticoid signaling are repressed, only a handful of them are known to be regulated by nGREs. These include pro-opiomelanocortin, $\mathrm{CRH}$, prolactin, and neuronal serotonin receptor.

\section{Gene Repression by Protein-Protein Interactions}

Most of the genes repressed by GR $\alpha$ occur via protein-protein interactions independent of DNA binding by the receptor (Fig. 2). This mechanism of signaling has been best characterized for the transcription factors $\mathrm{NF \kappa}$, activator protein-1 (AP-1), and Smad3. NFкB is a ubiquitous homo/heterodimer transcription factor most widely known for its role in inflammation that is composed of subunits from the Rel family of proteins (p50, p52, p65, RelB, and c-Rel). The p50/p65 heterodimer is the most common combination involved in transcriptional processes. ${ }^{51} \mathrm{In}$ cells, NFKB is kept in an inactive state in the cytoplasm by interactions with its inhibitor, IкB. ${ }^{51}$ Several stimuli (usually inflammatory) result in the activation of $\mathrm{I} \kappa \mathrm{B}$ kinase that phosphorylates I $\mathrm{B}$ to promote the dissocia-

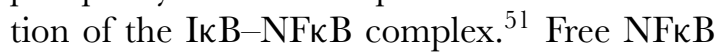
translocates into the nucleus, where it binds to DNA regulatory elements and activates gene transcription. ${ }^{51}$

GR $\alpha$ can physically bind to p65 and repress the NFкB-mediated transcription in several ways. For example, the interaction of GR $\alpha$ with p65 can result in the sequestering of

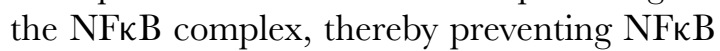
from reaching its DNA-binding site. ${ }^{52} \mathrm{GR} \alpha$ can also interact with DNA-bound $\mathrm{NF} \kappa \mathrm{B}$ to inhibit the recruitment of the transcriptional machin- ery. ${ }^{52}$ Furthermore, since GR $\alpha$ and NFкB require many of the same transcription activators, such as CBP or p300, it is believed that GR $\alpha$ can diminish the available pool of these factors, thereby negating their use by $\mathrm{NF} \kappa \mathrm{B} .{ }^{53}$ Finally, GR $\alpha$ can also suppress NFкB transactivation by interfering with the cellular machinery necessary for gene activation. In this regard, GR $\alpha$ has been reported to interfere with the NFкB-mediated phosphorylation of the RNA Polymerase II C-terminal tail, necessary for robust transcriptional activation. ${ }^{54}$ GR $\alpha$ has also been shown to obstruct p65mediated HAT activity while promoting the recruitment of histone deacetylase- 2 to NFKB target genes. ${ }^{55,56}$ Together, these effects increase chromatin tightening and result in decreased gene expression. Classical gene targets of $\mathrm{NF} \kappa \mathrm{B}$ that are repressed by $\mathrm{GR} \alpha$ include many pro-inflammatory cytokines and their receptors, such as tumor necrosis factor $\alpha(\mathrm{TNF} \alpha)$, interleukin-1 $\beta$, and granulocyte monocyte colony stimulating factor.

Similar to NFผB, GR $\alpha$ can bind and repress the transcriptional activity of AP-1. AP-1 is a homo/heterodimer transcription factor composed of Fos family (c-Fos, FosB, Fral, and Fra2) or Jun family members (c-Jun, JunB, and JunD). ${ }^{57}$ It binds to its DNA response element via a basic leucine zipper motif. A variety of stimuli can lead to phosphorylation of AP-1 complexes and greatly increase their transcriptional activity. GR $\alpha$ can physically interact with AP-1 and inhibit AP-1-mediated gene activation by employing similar mechanisms to the ones discussed for NFผB. ${ }^{58}$ Genes repressed by $\mathrm{GR} \alpha$ in an AP-1-dependent manner include collagenase, stromelysin, and other matrix metalloproteinases.

Inhibition of Smad signaling is yet another case where GR $\alpha$ can bind and repress the activity of a transcription factor. In this pathway, the activated tumor growth factor $\beta$ (TGF $\beta$ ) receptor phosphorylates Smad3 and promotes its association with Smad4. The Smad3-4 complex translocates into the nucleus and acts as a transcription factor by binding to DNA 
regulatory elements. Physical interactions with GR $\alpha$, however, greatly reduce the transcriptional activity of Smad3-4 complexes. ${ }^{59}$ It is unclear how GR $\alpha$ inhibits Smad3-mediated gene activation, but mechanisms similar to ones already discussed are probably at play. ${ }^{59,60}$ TGF $\beta$-Smad signaling is important for cell differentiation, extracellular matrix production, as well as immune and inflammatory responses. Other examples of GR $\alpha$-mediated gene repression by protein-protein interactions include transcription factors NF-AT and IRFs, both well known for their role in inflammation. ${ }^{46,53,61}$

\section{Signaling by Translational Isoforms}

As previously mentioned, alternative initiation sites in the mRNA transcript of GR $\alpha$ give rise to eight translational isoforms. ${ }^{27}$ The classic GR $\alpha$, with 777 amino acids, is actually isoform GR $\alpha$-A. The other seven isoforms, in descending order of molecular size, are GR $\alpha-\mathrm{B},-\mathrm{C} 1$, -C2, -C3, -D1, -D2, and -D3. All have identical DNA-binding and C-terminal ligand-binding domains but exhibit truncated $\mathrm{N}$-termini compared to GR $\alpha$-A. In the extreme case of GR $\alpha$ D3, for instance, the N-terminal domain is almost completely missing.

Despite having similar ligand affinity, these translational isoforms elicit different gene expression changes. In particular, it was recently found that isoform $\mathrm{GR} \alpha-\mathrm{C} 3$ is more efficient at inducing proapoptotic genes in human osteosarcoma cell lines than the classical GR $\alpha$ A. Conversely, isoform GR $\alpha-\mathrm{D} 3$ exhibited a decreased capacity to generate the same transcriptional responses. The molecular mechanism of action seems to involve an enhancement in the recruitment of coactivators by GR $\alpha-C 3$, and the opposite occurs with isoform GR $\alpha$-D $3{ }^{62}$ While the expression levels of these translational isoforms vary among tissues, it is still unknown what their physiological impact might be, or what factors determine their expression patterns.

\section{Secondary Signaling Mechanisms}

Primary GR $\alpha$-mediated changes in gene expression initiate countless other signaling events. For instance, glucocorticoid signaling has been shown to alter the mRNA turnover of $\mathrm{TNF} \alpha$, an inflammatory cytokine. Here, $\mathrm{GR} \alpha$ activation leads to the increased expression of tristetraprolin (TTP), a protein equipped with zinc finger domains capable of binding to mRNA molecules containing adenylateuridylate-rich elements (AREs) located in the $3^{\prime}$ untranslated regions. ${ }^{63}$ Association of TTP with AREs leads to the rapid decay of the target mRNA by recruitment of RNA degrading enzymes. ${ }^{64}$ GR $\alpha$-mediated gene induction of TTP increases the mRNA turnover of TNF $\alpha$ transcripts through AREs, and leads to a reduction in TNF $\alpha$ protein synthesis. ${ }^{63}$ Since many other mRNA transcripts contain AREs, it is possible that glucocorticoid signaling regulates the expression of other genes in this manner.

Glucocorticoids can also elicit secondary responses by altering the components of other signaling pathways. For instance, primary GR $\alpha$ signaling induces the expression of the mitogenactivated protein kinase (MAPK) phosphatase 1 (MKP1) gene. Increased expression of MKP1 leads to a decrease in MAPK signaling by dephosphorylating and inactivating the MAPK components JNK, ERK, and p38. ${ }^{65}$ The MAPK pathway is involved in diverse cellular processes, such as apoptosis, mitosis, and differentiation.

A change in the expression level of a transcription factor is yet another mechanism by which primary GR $\alpha$ signaling can lead to secondary cellular events. Glucocorticoids, for instance, silence the expression of ATF4, a basic leucine zipper transcription factor required for the expression of genes involved in amino acid biosynthetic enzymes, amino acid transporters, and aminoacyl-tRNA synthetases. ${ }^{66}$ 
Therefore, primary GR $\alpha$ signaling facilitates the switch from amino acid and protein anabolism to catabolism through the downregulation of ATF4. ${ }^{66}$ It is possible that many of the physiological actions ascribed to glucocorticoids are the result of secondary changes in gene expression mediated by transcription factors.

\section{Nongenomic Signaling}

In addition to the variety of genomic signaling mechanisms discussed, there is increasing evidence that glucocorticoids are capable of rapid signaling events independent of transcriptional changes. One of the most notable examples involves a reduction in the production of the pro-inflammatory molecule arachidonic acid (AA) by inhibition of the epidermal growth factor (EGF) signaling pathway (Fig. 2) ${ }^{67}$ Here, Src kinase, part of the multimeric complex sequestering GR $\alpha$, is released upon hormone binding and phosphorylates lipocortin-1. ${ }^{67}$ Phosphorylated lipocortin-1, in turn, displaces the adaptor protein Grb2 from active EGF receptors. Reduced EGF signaling through Grb2 results in diminished activity of cytoplasmic phospholipase $\mathrm{A}_{2}\left(\mathrm{cPLA}_{2}\right)$, whose enzymatic byproduct is AA. ${ }^{67}$ Another rapid, nontranscriptional event associated with glucocorticoids involves the phosphoinositide 3kinases (PI3Ks) signaling pathway, leading to protective effects on the cardiovascular system and the brain. Physical interaction of GR $\alpha$ with p85 $\alpha$, the main regulatory subunit of PI3Ks, can lead to increased PI3Ks activity and downstream signaling. ${ }^{68,69}$ Further research is necessary to determine the physiological relevance of these and other non-genomic signaling events mediated by GR $\alpha$.

\section{Summary}

In this chapter, we have reviewed several mechanisms by which glucocorticoids operate and elicit signaling events via the GR. Glucocorticoids are steroid hormones released by the adrenal cortex under situations of environmental or physiological stress. In the cell, glucocorticoids bind to the GR and elicit the disassembly of a multimeric protein complex sequestering the GR in the cytoplasm. Ligandbound GR translocates into the nucleus and alters gene expression via GREs or nGREs, both of which involve direct DNA binding. Alternatively, the GR also mediates transcriptional changes without direct DNA binding by physical interactions with transcriptional factors, such as STATs, NFкB, AP-1, and Smad3. Translational isoforms of the GR selectively regulate gene expression, and thus greatly increase GR signaling mechanisms. In addition, secondary signaling events of glucocorticoid action can affect mRNA turnover or alter the composition of other signaling cascades. Gene induction or repression of transcription factors by GR can further elicit secondary changes in gene expression. Finally, rapid nongenomic signaling events of glucocorticoid signaling involve the disassembly of the cytoplasmic complex sequestering GR, or cross-talk by protein-protein interactions with components of other signaling pathways. Clearly, the innumerable biological processes that glucocorticoid signaling influence are matched by an astonishing diversity of signaling mechanisms.

\section{Acknowledgments}

We thank Robert Oakley for careful review and editing of this manuscript.

\section{Conflicts of Interest}

The authors declare no conflicts of interest.

\section{References}

1. Chrousos, G.P. 1995. The hypothalamic-pituitaryadrenal axis and immune-mediated inflammation. N. Engl. F. Med. 332: 1351-1362. 
2. Barnes, P.J. 1998. Anti-inflammatory actions of glucocorticoids: molecular mechanisms. Clin. Sci. (Lond.) 94: $557-572$.

3. Newell-Price, J. 2008. Cushing's syndrome. Clin. Med. 8: $204-208$.

4. Nieman, L.K. \& M.L. Chanco Turner. 2006. Addison's disease. Clin. Dermatol. 24: 276-280.

5. Robinson-Rechavi, M., A.S. Carpentier, M. Duffraisse, et al. 2001. How many nuclear hormone receptors are there in the human genome? Trends Genet. 17: 554-556.

6. Thornton, J.W. 2001. Evolution of vertebrate steroid receptors from an ancestral estrogen receptor by ligand exploitation and serial genome expansions. Proc. Natl. Acad. Sci. USA 98: 5671-5676.

7. Cole, T.J., J.A. Blendy, A.P. Monaghan, et al. 1995. Targeted disruption of the glucocorticoid receptor gene blocks adrenergic chromaffin cell development and severely retards lung maturation. Genes Dev. 9: 1608-1621.

8. Brewer, J.A., B. Khor, S.K. Vogt, et al. 2003. T-cell glucocorticoid receptor is required to suppress COX2-mediated lethal immune activation. Nat. Med. 9: 1318-1322.

9. Bhattacharyya, S., D.E. Brown, J.A. Brewer, et al. 2007. Macrophage glucocorticoid receptors regulate Toll-like receptor 4-mediated inflammatory responses by selective inhibition of p38 MAP kinase. Blood 109: 4313-4319.

10. Opherk, C., F. Tronche, C. Kellendonk, et al. 2004. Inactivation of the glucocorticoid receptor in hepatocytes leads to fasting hypoglycemia and ameliorates hyperglycemia in streptozotocininduced diabetes mellitus. Mol. Endocrinol. 18: 13461353.

11. Tronche, F., C. Opherk, R. Moriggl, et al. 2004. Glucocorticoid receptor function in hepatocytes is essential to promote postnatal body growth. Genes Dev. 18: 492-497.

12. Tronche, F., G. Kellendonk, O. Kretz, et al. 1999. Disruption of the glucocorticoid receptor gene in the nervous system results in reduced anxiety. Nat. Genet. 23: 99-103.

13. Boyle, M.P., B.J. Kolber, S.K. Vogt, et al. 2006. Forebrain glucocorticoid receptors modulate anxietyassociated locomotor activation and adrenal responsiveness. f. Neurosci. 26: 1971-1978.

14. Kim, H.J., H. Zhao, H. Kitaura, et al. 2006. Glucocorticoids suppress bone formation via the osteoclast. 7. Clin. Invest. 116: 2152-2160.

15. Encio, I.J. \& S.D. Detera-Wadleigh. 1991. The genomic structure of the human glucocorticoid receptor. F. Biol. Chem. 266: 7182-7188.

16. Oakley, R.H., M. Sar \& J.A. Cidlowski. 1996. The human glucocorticoid receptor beta isoform. Expres- sion, biochemical properties, and putative function. 7. Biol. Chem. 271: 9550-9559.

17. Presul, E., S. Schmidt, R. Kofler, et al. 2007. Identification, tissue expression, and glucocorticoid responsiveness of alternative first exons of the human glucocorticoid receptor. F. Mol. Endocrinol. 38: 7990.

18. Turner, J.D., A.B. Schote, J.A. Macedo, et al. 2006. Tissue specific glucocorticoid receptor expression, a role for alternative first exon usage? Biochem. Pharmacol. 72: 1529-1537.

19. Zong, J., J. Ashraf \& E.B. Thompson. 1990. The promoter and first, untranslated exon of the human glucocorticoid receptor gene are GC rich but lack consensus glucocorticoid receptor element sites. Mol. Cell Biol. 10: 5580-5585.

20. Oakley, R.H., J.C. Webster, M. Sar, et al. 1997. Expression and subcellular distribution of the betaisoform of the human glucocorticoid receptor. Endocrinology 138: 5028-5038.

21. Oakley, R.H., G.M. Jewell, M.R. Yudt, et al. 1999. The dominant negative activity of the human glucocorticoid receptor beta isoform. Specificity and mechanisms of action. F. Biol. Chem. 274: 2785727866.

22. Lewis-Tuffin, L.J. \& J.A. Cidlowski. 2006. The physiology of human glucocorticoid receptor beta (hGRbeta) and glucocorticoid resistance. Ann. N. Y. Acad. Sci. 1069: 1-9.

23. Lewis-Tuffin, L.J., C.M. Jewell, R.J. Bienstock, et al. 2007. Human glucocorticoid receptor beta binds RU-486 and is transcriptionally active. Mol. Cell Biol. 27: 2266-2282.

24. Moalli, P.A., S. Pillay, N.L. Krett, et al. 1993. Alternatively spliced glucocorticoid receptor messenger RNAs in glucocorticoid-resistant human multiple myeloma cells. Cancer Res. 53: 3877-3879.

25. Krett, N.L., S. Pillay, P.A. Moalli, et al. 1995. A variant glucocorticoid receptor messenger RNA is expressed in multiple myeloma patients. Cancer Res. 55: 27272729 .

26. Beger, C., K. Gerdes, M. Lauten, et al. 2003. Expression and structural analysis of glucocorticoid receptor isoform gamma in human leukaemia cells using an isoform-specific real-time polymerase chain reaction approach. Br. F. Haematol. 122: 245-252.

27. Lu, N.Z. \& J.A. Cidlowski. 2005. Translational regulatory mechanisms generate N-terminal glucocorticoid receptor isoforms with unique transcriptional target genes. Mol Cell. 18: 331-342.

28. Lu, N.Z. \& J.A. Cidlowski. 2006. Glucocorticoid receptor isoforms generate transcription specificity. Trends Cell Biol. 16: 301-307.

29. Kumar, R., D.E. Volk, J. Li, et al. 2004. TATA box binding protein induces structure in the recombinant 
glucocorticoid receptor AF1 domain. Proc. Natl. Acad. Sci. USA 101: 16425-16430.

30. Kumar, R. \& E.B. Thompson. 2005. Gene regulation by the glucocorticoid receptor: structure:function relationship. F. Steroid Biochem. Mol. Biol. 94: 383-394.

31. Bledsoe, R.K., V.G. Montana, T.B. Stanley, et al. 2002. Crystal structure of the glucocorticoid receptor ligand binding domain reveals a novel mode of receptor dimerization and coactivator recognition. Cell 110: 93-105.

32. Duma, D., G.M. Jewell \& J.A. Cidlowski. 2006. Multiple glucocorticoid receptor isoforms and mechanisms of post-translational modification. F. Steroid Biochem. Mol. Biol. 102: 11-21.

33. Webster, J.G., G.M. Jewell, J.E. Bodwell, et al. 1997. Mouse glucocorticoid receptor phosphorylation status influences multiple functions of the receptor protein. F. Biol. Chem. 272: 9287-9293.

34. Chen, W., T. Dang, R.D. Blind, et al. 2008. Glucocorticoid receptor phosphorylation differentially affects target gene expression. Mol. Endocrinol 22: 1754 1766.

35. Le Drean, Y., N. Mincheneau, P. Le Goff, et al. 2002. Potentiation of glucocorticoid receptor transcriptional activity by sumoylation. Endocrinology 143: 3482-3489.

36. Dittmar, K.D., D.R. Demady, L.F. Stancato, et al. 1997. Folding of the glucocorticoid receptor by the heat shock protein (hsp) 90-based chaperone machinery. The role of $\mathrm{p} 23$ is to stabilize receptor.hsp90 heterocomplexes formed by hsp90.p60.hsp70. 7. Biol. Chem. 272: 21213-21220.

37. Hawle, P., M. Siepmann, A. Harst, et al. 2006. The middle domain of Hsp90 acts as a discriminator between different types of client proteins. Mol. Cell Biol. 26: $8385-8395$.

38. Schoneveld, O.J., I.C. Gaemers \& W.H. Lamers. 2004. Mechanisms of glucocorticoid signalling. Biochim. Biophys. Acta 1680: 114-128.

39. Wieland, S., M.D. Schatt \& S. Rusconi. 1990. Role of TATA-element in transcription from glucocorticoid receptor-responsive model promoters. Nucleic Acids Res. 18: $5113-5118$.

40. Jantzen, H.M., U. Strahle, B. Gloss, et al. 1987. Cooperativity of glucocorticoid response elements located far upstream of the tyrosine aminotransferase gene. Cell 49: 29-38.

41. Ford, J., I.J. McEwan, A.P. Wright, et al. 1997. Involvement of the transcription factor IID protein complex in gene activation by the N-terminal transactivation domain of the glucocorticoid receptor in vitro. Mol. Endocrinol. 11: 1467-1475.

42. Glass, G.K. \& M.G. Rosenfeld. 2000. The coregulator exchange in transcriptional functions of nuclear receptors. Genes Dev. 14: 121-141.
43. Rosenfeld, M.G. \& C.K. Glass. 2001. Coregulator codes of transcriptional regulation by nuclear receptors. F. Biol. Chem. 276: 36865-36868.

44. Wallberg, A.E., K.E. Neely, J.A. Gustafsson, et al. 1999. Histone acetyltransferase complexes can mediate transcriptional activation by the major glucocorticoid receptor activation domain. Mol. Cell Biol. 19: 5952-5959.

45. Nagaich, A.K., D.A. Walker, R. Wolford, et al. 2004. Rapid periodic binding and displacement of the glucocorticoid receptor during chromatin remodeling. Mol Cell. 14: 163-174.

46. Schindler, C. 1999. Cytokines and JAK-STAT signaling. Exp. Cell Res. 253: 7-14.

47. Zhang, Z., S. Jones, J.S. Hagood, et al. 1997. STAT3 acts as a co-activator of glucocorticoid receptor signaling. F. Biol. Chem. 272: 30607-30610.

48. Biola, A., K. Andreau, M. David, et al. 2000. The glucocorticoid receptor and STAT6 physically and functionally interact in T-lymphocytes. FEBS Lett. 487: 229-233.

49. Meyer, T., J. Carlstedt-Duke \& D.B. Starr. 1997. A weak TATA box is a prerequisite for glucocorticoiddependent repression of the osteocalcin gene. F. Biol. Chem. 272: 30709-30714.

50. Novac, N., D. Baus, A. Dostert, et al. 2006. Competition between glucocorticoid receptor and $\mathrm{NF} \kappa \mathrm{B}$ for control of the human FasL promoter. Faseb 7. 20: 1074-1081.

51. Ghosh, S. \& M. Karin. 2002. Missing pieces in the NF-кB puzzle. Cell 109(Suppl): S81-96.

52. McKay, L.I. \& J.A. Cidlowski. 1998. Cross-talk between nuclear factor- $\kappa \mathrm{B}$ and the steroid hormone receptors: mechanisms of mutual antagonism. Mol. Endocrinol. 12: 45-56.

53. Almawi, W.Y. \& O.K. Melemedjian. 2002. Negative regulation of nuclear factor- $\mathrm{\kappa B}$ activation and function by glucocorticoids. 7. Mol. Endocrinol. 28: 6978.

54. Nissen, R.M. \& K.R. Yamamoto. 2000. The glucocorticoid receptor inhibits NFkB by interfering with serine-2 phosphorylation of the RNA polymerase II carboxy-terminal domain. Genes Dev. 14: 2314 2329.

55. Ito, K., P.J. Barnes \& I.M. Adcock. 2000. Glucocorticoid receptor recruitment of histone deacetylase 2 inhibits interleukin-lbeta-induced histone $\mathrm{H} 4$ acetylation on lysines 8 and 12. Mol. Cell Biol. 20: 68916903.

56. Ito, K., S. Yamamura, S. Essilfie-Quaye, et al. 2006. Histone deacetylase 2-mediated deacetylation of the glucocorticoid receptor enables NF-кB suppression. f. Exp. Med. 203: 7-13.

57. Shaulian, E. \& M. Karin. 2002. AP-1 as a regulator of cell life and death. Nat. Cell Biol. 4: E131-E136. 
58. Schule, R., P. Rangarajan, S. Kliewer, et al. 1990. Functional antagonism between oncoprotein c-Jun and the glucocorticoid receptor. Cell 62: 12171226.

59. Song, C.Z., X. Tian \& T.D. Gelehrter. 1999. Glucocorticoid receptor inhibits transforming growth factor- $\beta$ signaling by directly targeting the transcriptional activation function of Smad3. Proc. Natl. Acad. Sci. USA 96: 11776-11781.

60. Li, G., S. Wang \& T.D. Gelehrter. 2003. Identification of glucocorticoid receptor domains involved in transrepression of transforming growth factor-beta action. f. Biol. Chem. 278: 41779-41788.

61. O’Neill, L.A. 2006. How Toll-like receptors signal: what we know and what we don't know. Curr. Opin. Immunol. 18: 3-9.

62. Lu, N.Z., J.B. Collins, S.F. Grissom, et al. 2007. Selective regulation of bone cell apoptosis by translational isoforms of the glucocorticoid receptor. Mol. Cell Biol. 27: 7143-7160.

63. Smoak, K. \& J.A. Cidlowski. 2006. Glucocorticoids regulate tristetraprolin synthesis and posttranscriptionally regulate tumor necrosis factor $\alpha$ inflammatory signaling. Mol. Cell Biol. 26: 9126-9135.

64. Ishmael, F.T., X. Fang, M.R. Galdiero, et al. 2008. Role of the RNA-binding protein tristetraprolin in glucocorticoid-mediated gene regulation. 7. Immunol. 180: 8342-8353.

65. Abraham, S.M., T. Lawrence, A. Kleiman, et al. 2006. Antiinflammatory effects of dexamethasone are partly dependent on induction of dual specificity phosphatase 1.F. Exp. Med. 203: 1883-1889.

66. Adams, C.M. 2007. Role of the transcription factor ATF4 in the anabolic actions of insulin and the antianabolic actions of glucocorticoids. F. Biol. Chem. 282: 16744-16753.

67. Croxtall, J.D., Q. Choudhury \& R.J. Flower. 2000. Glucocorticoids act within minutes to inhibit recruitment of signalling factors to activated EGF receptors through a receptor-dependent, transcriptionindependent mechanism. Br. F. Pharmacol. 130: 289 298.

68. Hafezi-Moghadam, A., T. Simoncini, Z. Yang, et al. 2002. Acute cardiovascular protective effects of corticosteroids are mediated by non-transcriptional activation of endothelial nitric oxide synthase. Nat. Med. 8: $473-479$.

69. Limbourg, F.P., Z. Huang, J.C. Plumier, et al. 2002. Rapid nontranscriptional activation of endothelial nitric oxide synthase mediates increased cerebral blood flow and stroke protection by corticosteroids. f. Clin. Invest. 110: 1729-1738. 